\title{
The Immunoexpression of FSH-R in the Ductuli Efferentes and the Epididymis of Men and Rat: Effect of FSH on the Morphology and Steroidogenic Activity of Rat Epididymal Epithelial Cells In Vitro
}

\author{
Małgorzata Świder-Al-Amawi, ${ }^{1}$ Agnieszka Kolasa, ${ }^{1}$ Andrzej Sikorski, ${ }^{2}$ Mariola Marchlewicz, ${ }^{1}$ \\ Irena Baranowska-Bosiacka, ${ }^{3}$ and Barbara Wiszniewska ${ }^{1}$ \\ ${ }^{1}$ Department of Histology and Embryology, Pomeranian Medical University, 72 Powstańców Wlkp. Street, 70-111 Szczecin, Poland \\ ${ }^{2}$ Department of Urology, Pomeranian Medical University, 72 Powstańców Wlkp. Street, 70-111 Szczecin, Poland \\ ${ }^{3}$ Department of Biochemistry and Human Nutrition, Pomeranian Medical University, 48 Żolnierska Street, 71-210 Szczecin, Poland \\ Correspondence should be addressed to Barbara Wiszniewska, barbwisz@sci.pam.szczecin.pl
}

Received 20 July 2009; Revised 20 November 2009; Accepted 5 March 2010

Academic Editor: Pavel Hozak

Copyright () 2010 Małgorzata Świder-Al-Amawi et al. This is an open access article distributed under the Creative Commons Attribution License, which permits unrestricted use, distribution, and reproduction in any medium, provided the original work is properly cited.

\begin{abstract}
The Sertoli cells were regarded as the only target for FSH in male reproductive system. The expression of FSH receptor (FSH-R) was detected also in epithelial cells of the caput epididymis of rat and monkey. We showed in the immunohistochemistry study the expression of FSH-R in rat and human ductuli efferentes and the caput, corpus, and cauda epididymis, moreover, by Western blot analysis in the caput and cauda epididymis of rat. Additionally, we presented that the morphology of rat epididymal epithelial cells in vitro was affected by FSH, and FSH stimulation resulted in the increase of $17 \beta$-estradiol synthesis by rat caput epididymal cells in dose-depended manner. In conclusion, the identification of FSH receptors in human and rat epididymides supports our results that the epididymis is a target organ not only for LH but additionally for FSH. On the basis of the results we showed for the first time that morphology of epididymal epithelial cells and epididymal steroidogenesis can be regulated by FSH.
\end{abstract}

\section{Introduction}

The function of the epididymis, including production of the epididymal specific microenvironment necessary for the maturation, storage, and survival of spermatozoa, is regulated by hormones and testicular growth factors. The crucial role plays testosterone, synthesized in Leydig cells under LH control, exerts the effect by LH receptors. Testosterone is transported from testis in complex with ABP, produced by Sertoli cells of seminiferous epithelium under FSH control. In the epididymis, testosterone is reduced into $5 \alpha$-dihydrotestosterone (DHT), the more biological active metabolite, due to the activity of $5 \alpha$-reductase. Investigations of last years delivered strong evidences, that functions of ductuli efferentes and ductus epididymis are modulated additionally by estrogens. However, the epididymis is also a source of all the steroids, and epididymal epithelial cells express receptors for them. There has been reported recently, that the cytoplasm of epithelial cells in the epididymis contains enzymes following steps of steroidogenesis and the cells are able to synthesize testosterone de novo and convert substrates of earlier steps of steroidogenesis into testosterone [1-5]. There are two isoforms of $5 \alpha$-reductase, type 1 and type 2 ( $5 \alpha$-red 1 and 2 ) in epididymis, the enzyme irreversible converting T into DHT [6]. Additionally, the expression of cytochrome $\mathrm{P} 450$ aromatase (P450arom) is found within epididymal epithelial cells of men and various animals [7-11]. Moreover, the activity of the enzyme resulted in $17 \beta$-estradiol (E2) production by cultured epididymal epithelial cells [11-13] and caudal minces of rat epididymis in vitro [10].

The presence of LH receptors in epididymal epithelial cells in vivo and in vitro indicates the regulatory effect of the gonadotropin on the epididymal steroidogenesis $[10,12]$. 
In former study we showed that hCG, exerting the effect in the same way as LH, affected the morphology of epididymal epithelial cells in vitro and modulated steroidogenesis in the cells [12]. The cytoplasm of the cultured cells under hCG influence was richer in PAS-positive substances and lipid droplets than the cytoplasm of cells without hCG stimulation. Moreover, the concentration of E2 released into the culture medium by stimulating cells was statistically higher than that in nonstimulated cells [12]. In the respect of study showing the expression of receptors for FSH (FSH-R) in the epithelium of monkey and rat cauda epididymis [14], it is interesting to estimate the possibility of FSH influence, like LH, on the morphology of cultured epididymal epithelial cells and E2 synthesis by the cells. According to the two-cell theory, the ovarian steroidogenesis includes two cellular compartments and takes place under influence LH and FSH. LH stimulates the theca interna cells to production of androgens, while FSH promotes aromatization of androgens into estrogens in the granulosa cell of ovary follicles. It can be expected that the similar type of regulation of hormone synthesis takes place in the epididymis.

The aim of this study was to confirm the presence FSH-R in the epididymis and estimate the morphology of epididymal epithelial cells under FSH stimulation and to control the likely effect of FSH on synthesis of E2 by these cells, to better understand the hormonal regulation in this part of male reproductive tract.

\section{Materials and Methods}

2.1. Experimental Design. The experiment was carried out on 10 adult Wistar rats, weighing 300-350 g each. The rats were maintained at controlled temperature $\left(22-24^{\circ} \mathrm{C}\right)$ and photoperiod of LD 12:12 hours. The animals were anaesthetized with Thiopental (Biochemie GmbH, Kundl-Austria) (90 mg/kg body weight). The rat epididymides $(n=5)$ were used for immunohistochemical studies and for isolation of epididymal epithelial cells for culture $(n=5)$. Additionally, the FSH-R immunovisualization was carried out in human epididymis $(n=5)$. The epididymides were obtained from untreated patients after orchidectomy due to the prostate cancer. For immunostaining the caput, the corpus and the cauda epididymis were fixed for 24 hours at $4^{\circ} \mathrm{C}$ in $4 \%$ formaldehyde freshly prepared from paraformaldehyde and embedded in paraffin. The experiment received the approval of the Local Ethics Committee.

2.2. Isolation and Culture of Epididymal Epithelial Cells. The procedure of epididymal epithelial cells isolation and culture has been describe previously $[11,13]$. The procedure yielded small segments of epididymal duct without the outer sheath of connective tissue, smooth muscle cells, and spermatozoa. The viability of the isolated cells was detected by the trypan blue exclusion test. The isolated cells were transferred into plastic Petri culture dishes (Nunc Inc., Naperville, Il., USA) with cover slips on the bottom and cultured in Dulbecco's modified Eagle's medium
$5 \mathrm{~mL} /$ dish (Gibco BRL, Grand Island, USA) supplemented with 5\% inactivated fetal calf serum (FCS; Gibco BRL, Grand Island, USA) with/without $1 \mathrm{nmol} / \mathrm{L}$ dihydrotestosterone (DHT; Sigma Chemical Co, St Louis MO, USA), and with/without supplementation with FSH, pure serum gonadotropin (Folligon, Intervet International B.V. Boxmeer, Holland) in finally concentration $0.4 \mathrm{IU} / \mathrm{mL}$ medium or $0.8 \mathrm{IU} / \mathrm{mL}$ medium. The cells were cultured at $34^{\circ} \mathrm{C}$, in $5 \% \mathrm{CO}_{2}$ for 3 days, until they formed a monolayer. Thereafter, the medium was changed and the cells were cultured for the next two days. After that time, the cultures of epididymal epithelial cells stained with Oil Red $\mathrm{O}$ and with PAS-method [15] were used for morphological evaluation.

\subsection{Follicle-Stimulating Hormone (FSH) Receptor (FSH-R)} Immunohistochemistry. Paraffin-embedded sections $(5 \mu \mathrm{m}$ thick) of rat and human caput, corpus, and cauda epididymides were immunostained for visualization of Folliclestimulating hormone receptor (FSH-R). The immunohistochemistry (IHC) was performed using rabbit polyclonal anti-FSH-R antibody (diluted 1 : 200) (FSH-R; H-190: sc13935 Santa Cruz Biotechnology, INC). The antibody is raised against amino acids 1-190 mapping at the $\mathrm{N}$-terminus of follicle-stimulating hormone receptor (FSH-R) of human origin and recommended for detection of FSH-R of mouse, rat, and human origin.

The deparaffinized sections were microwave irradiated in citrate buffer ( $\mathrm{pH} \mathrm{6.0)}$ to heat-induced epitope retrieval. After slow cooling to room temperature the slides were washed in PBS twice for 5 minutes and then incubated with primary anti-FSH-R antibody at $4^{\circ} \mathrm{C}$ overnight. For visualization of FSH-R-positive cells and avidin-biotinperoxidase system with diaminobenzidine as the chromogen (EnVision ${ }^{+}$System-HRP (DAB) Code K4011 DakoCytomation, Glostrup, Denmark) was used according to the manufacturer's instruction. Sections were washed in distillated $\mathrm{H}_{2} \mathrm{O}$ and counterstained with hematoxylin. For negative control, specimens were processed in the absence of primary antibody. Positive staining was defined microscopically by visual identification of brown pigmentation.

2.4. Western Blot Analysis. Total cellular protein of the testis, the caput, and cauda epididymis as well as skeletal muscle of rat was extracted in RIPA buffer (Tris- $\mathrm{HCl}, 50 \mathrm{mM}$, pH 7.4; NP-40, 1\%; sodium deoxycholate, $0.25 \% ; \mathrm{NaCl}$, $150 \mathrm{mM}$; EDTA, $1 \mathrm{mM}$; PMSF, $1 \mathrm{mM}$ ) in the presence of $0.1 \%$ EDTA-free protease inhibitor cocktail, $1 \mathrm{mM}$ sodium orthovanadate, and $1 \mathrm{mM}$ sodium fluoride. Protein concentration was quantified using the bichoninic acid assay (BCA; Pierce Biotechnology,) according to the manufacturer's instructions. Cell lysates $(50 \mu \mathrm{g})$ were prepared with reducing sample buffer and separated through a 10\% SDSPAGE gel followed by semidry transfer to a PVDF membrane. Membranes were blocked in 5\% milk-TBST, followed by 2-hour incubation with appropriate primary antibodies: anti-FSHR (H-190; 1 : 100; Santa Cruz) anti- $\beta$-actin (1 : 1000; Santa Cruz). Bound antibody was visualized 


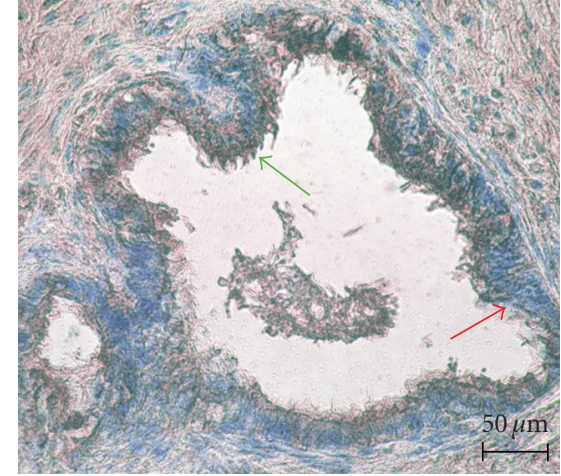

(a)

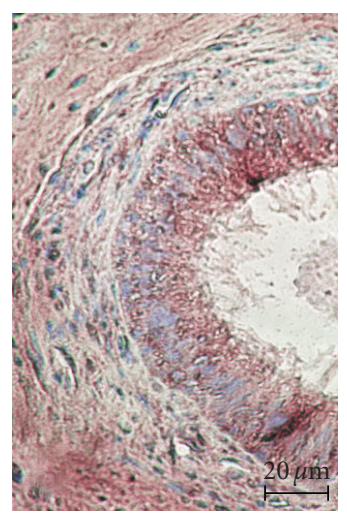

(c)

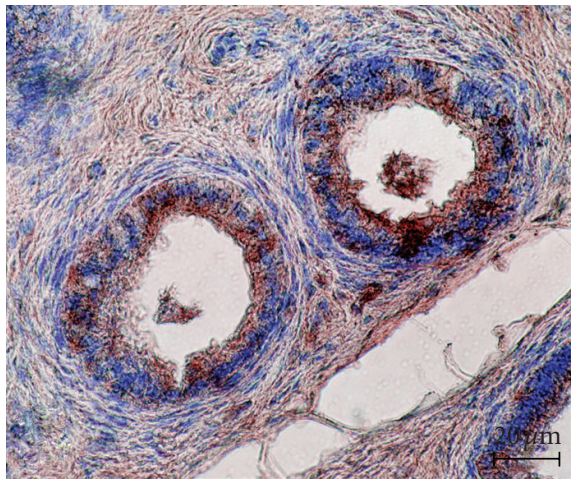

(b)

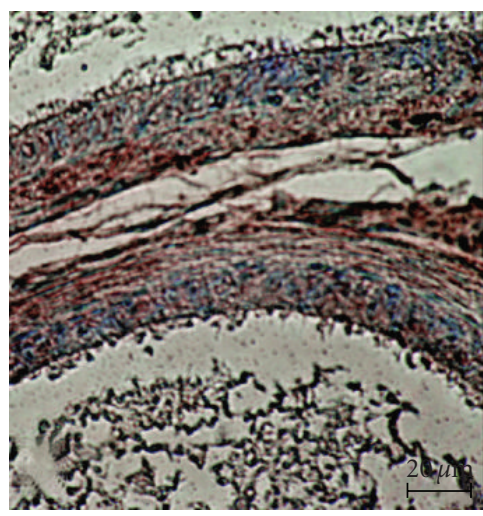

(d)

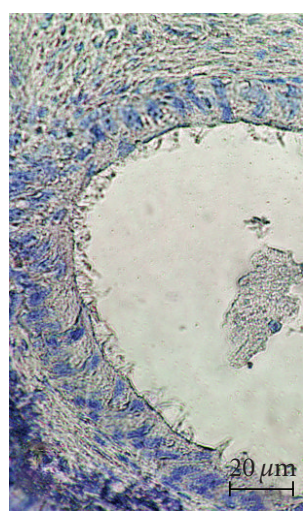

(e)

FIGURE 1: The distribution of FSH-R in the ductuli efferentes (a) and in the ductus epididymis (b-d) of rat. (a) Immunostaining of FSH-R in the apical cytoplasm of nonciliated cells (red arrow) and ciliated cells (green arrow) of ductuli efferentes. (b) The strong intensity of immunoreactions in all principal cells of the caput epididymis. (c-d) The decreased staining in the principal cells of the corpus (c) and the cauda (d) epididymis. (e) The lack of immunostaining in cells of the epididymal epithelium in negative control of reaction with omitting of primary antibody. Scale bar: (a) $50 \mu \mathrm{m}$, (b-e) $20 \mu \mathrm{m}$.

with horseradish peroxidase-conjugated secondary antibodies (GE Biosciences) and chemiluminescence-based detection system (SuperWest Pico; Pierce). Finally, the membrane was exposed to an autoradiography film (Hyperfilm; GE Biosciences).

2.5. Hormone Assay. For hormone assay the epididymal epithelial cells were placed into 24-multicell culture dishes (Corning, USA) - 500,000 cell/well. The cells were cultured in $1 \mathrm{~mL}$ of Dulbecco's modified Eagle's medium without phenol red (Gibco BRL, Grand Island, USA), supplemented with 5\% FSC, without/with DHT, and in supplementation with FSH in doses $0.4 \mathrm{IU}$ or $0.8 \mathrm{IU} / \mathrm{mL}$ medium.

Centrifuged media from epididymal epithelial cells cultured for 3 and 5 days were designed for $17 \beta$-estradiol (E2) assays. The concentration of E2 was estimated in the culture media enriched with 5\% FCS before initiation of the cell culture (control media) and in media on the 3rd and 5th days of the culture. Levels of E2 were estimated by Enzyme Linked Fluorescent Assay (Bio Merieux, France) VIDAS Estradiol II (E2II), the sensitivity of which is in the range from 5 to $4300 \mathrm{pg} / \mathrm{mL}$.
2.6. Statistical Analysis. Nonparametric Mann-Whitney $U$ test for variables with distributions different from normal (Shapiro-Wilk's test) and Student $t$-test for normally distributed variables were used to check significance of differences between study and control groups. The value of $P<.05$ was considered to indicate statistically significant differences. Calculations were done using the Statistica 5.0 Program PL for Windows (StatSoft, Poland).

\section{Results}

3.1. Immunolocalization of FSH-R. Immunostaining for FSH-R was detected in all studied segments of rat and men epididymides. The product of immunoreaction localizing of FSH-R protein was restricted to the cytoplasm of epithelial cells; there was no immunostaining in nuclei of the cells.

In the epithelium of the rat ductuli efferentes the immunoexpression of FSH-R was observed in the basal and apical cytoplasm of nonciliated cells (red arrow) and in apical cytoplasm of ciliated cells (green arrow) (Figure 1(a)). In the epithelium of the caput epididymis, the immunostaining was detected mainly in apical cytoplasm of principal cells; however a few epithelial cells contain the IHC-reaction 


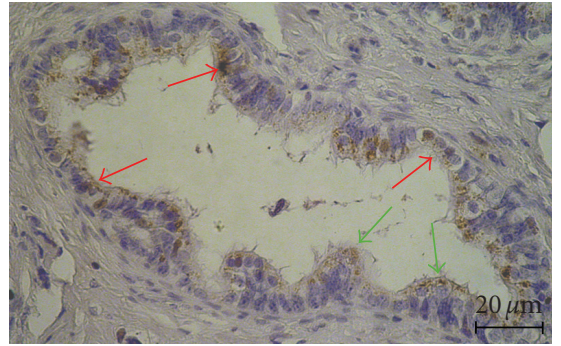

(a)

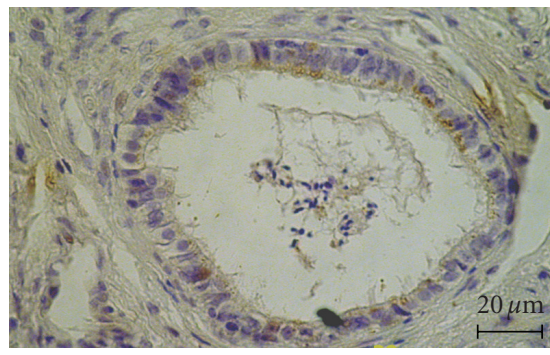

(c)

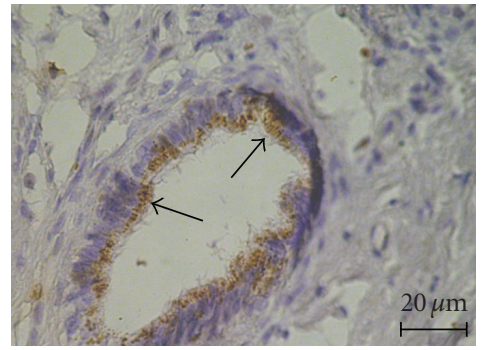

(b)

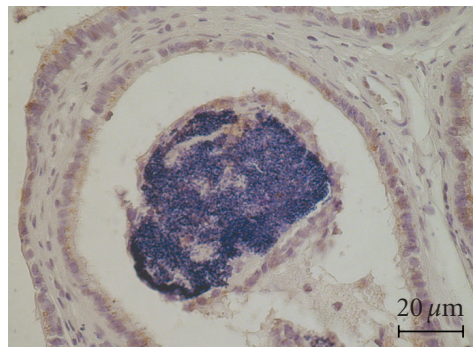

(d)

FIgure 2: The distribution of FSH-R in the ductuli efferentes (a) and the epididymis (b-d) of man. (a) The cytoplasm of nonciliated (red arrow) and the apical cytoplasm of ciliated cells (green arrow) of the ductuli efferentes was positive for FSH-R. (b) The immunoreaction for FSH-R was more intensive in the apical cytoplasm of all principal cells of the caput epididymis (black arrows). (c-d) The decreasing intensity in the cytoplasm of groups of principal cells of the corpus (c) and the cauda epididymis (d) Scale bar: $20 \mu \mathrm{m}$.

product in basal and apical cytoplasm (Figure 1(b)). In the corpus (Figure 1(c)) and cauda (Figure 1(d)) epididymis, FSH-R protein was noted in the same pattern; however decreasing intensity of immunoexpression was observed, with lowest intensity in principal cells of the corpus, and the cauda epididymis (Figures $1(\mathrm{c})$ and $1(\mathrm{~d})$ ). There was no immunoreaction in specimens of the caput, the corpus and the cauda epididymides incubated without primary antibody (Figure 1(e)).

In the human section of the ductuli efferentes epithelium FSH-R was expressed in nonciliated and ciliated cells. In nonciliated cells (red arrow) the immunostaining was observed in the whole cytoplasm, while in ciliated cells (green arrow) was located in the apical part of cytoplasm (Figure 2(a)). In the epithelium of the caput epididymis the FSH-R immunoexpression was found in the apical cytoplasm of all principal cells (black arrow) (Figure 2(b)). The intensity of immunostaining was decreased in the corpus and the cauda epididymis. The group of principal cells showed immunoreactivity and the product of immunoreactions was concentrated in the apical cytoplasm of the cells, both in the corpus (Figure 2(c)) and the cauda (Figure 2(d)) epididymis of men.

3.2. Light Microscopic Studies. After three days of culture, epithelial cells of the caput and cauda epididymides adhered to the bottom of culture dishes. The epididymal epithelial cells cultured with exogenous DHT formed a confluent monolayer. The cytoplasm of the cells was rich in PASpositive substances, glycogen deposits (Figure 3(a)), and lipid droplets (Figure 3(b)). The epididymal epithelial cells cultured in medium without DHT did not form confluent culture. They were stellate in the shape and were connected by cytoplasmic processes. The cytoplasm of the cells cultured in the medium without DHT was poor in glycogen, PASpositive substances (Figure 3(c)) and showed the decreased amount of lipid droplets. (Figure 3(d)). After FSH stimulation the epididymal epithelial cells cultured without DHT formed monolayer, similar to the cells cultured with DHT. However, the cytoplasm of the cells was also poor in PAS-positive substances and glycogen (Figure 3(e)), and contained lipid droplets (Figure 3(f)) in amount similar to that observed in the cytoplasm of cells cultured with DHT.

3.3. Western Blot Analysis for the Expression of FSH-R in the Caput and Cauda Epididymis of Rat. Western blotting of total cell extracts showed the presence of FSH-R protein in Figure 4(a) the testis, Figure 4(c) the caput epididymis, and Figure 4(d) the cauda epididymis of rat. No signal was seen in a rat skeletal muscle Figure 4(b) that served as a negative control. All tested samples showed the presence of actin (Figure 4).

3.4. Hormone Assay. The concentration of $17 \beta$-estradiol (E2) detected in the medium on day 3 of cell culture was considered as a basal. The concentration of E2 in the medium on day 5 of cell culture was considered to result from de novo synthesis. The level of E2 in control media was $31.6 \pm 6.4$ $(n=8)$.

The concentration of E2 in the culture media where the cells of the caput and cauda epididymides were cultured without DHT (-DHT) was compared to the concentration 


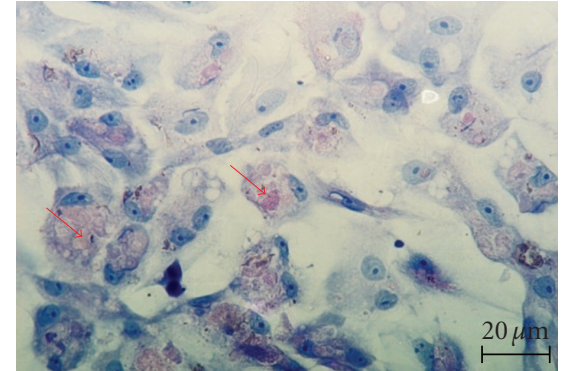

(a)

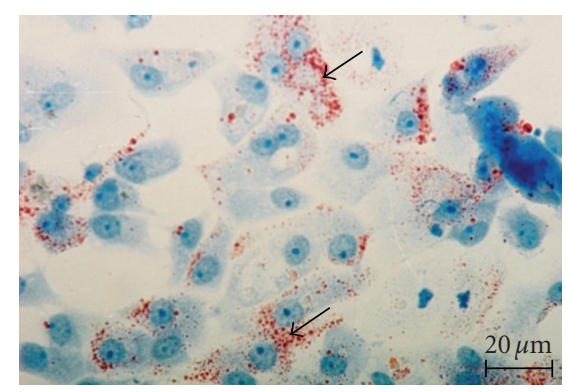

(d)

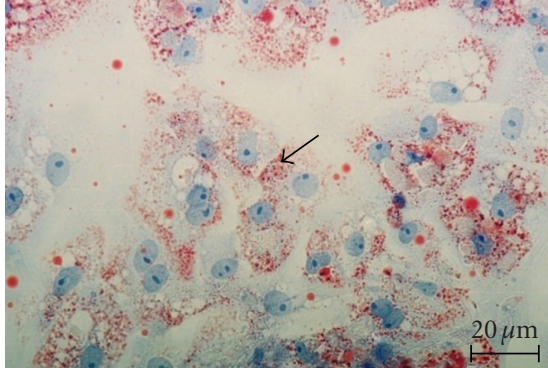

(b)

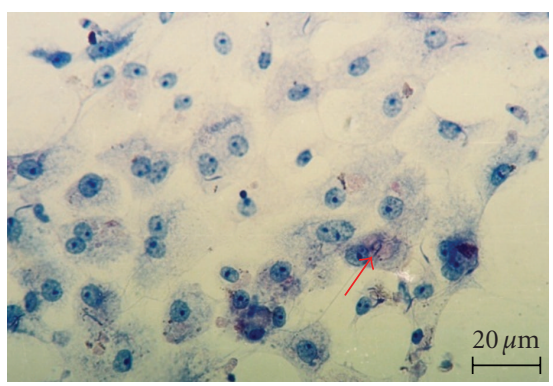

(e)

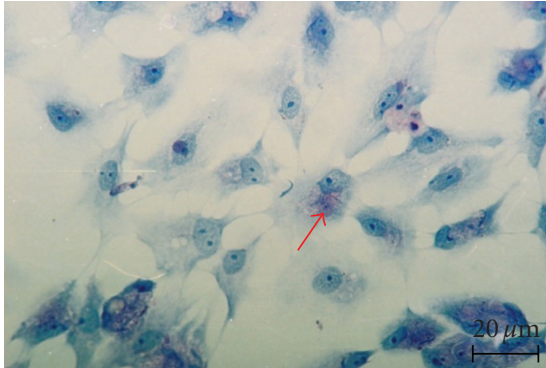

(c)

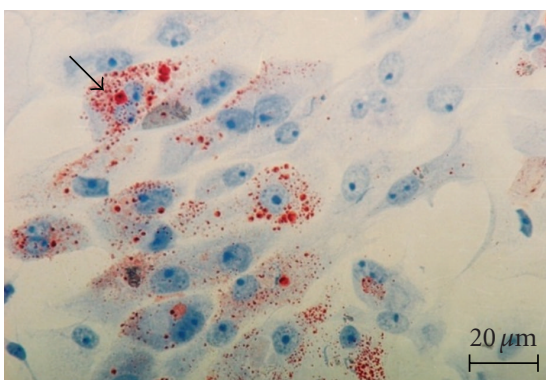

(f)

Figure 3: The 5th-day culture of epididymal epithelial cells: epididymal epithelial cells cultured in medium with DHT. The cells form confluent monolayer. The cytoplasm is rich in PAS-positive substances (red arrows) and glycogen (a) and lipid droplets (black arrows) (b). Epididymal epithelial cells are cultured without DHT. The cells stellate in the shape connected by cytoplasmic processes. The cytoplasm are poor in PAS-positive substances and glycogen (c) and lipid droplets (black arrows) (d). Epididymal epithelial cells are cultured without DHT in supplementation with $0.8 \mathrm{IU} / \mathrm{mL}$ FSH. The cytoplasm is poor in PAS-positive substances (red arrow) and in glycogen (e), and rich in lipid droplets (black arrow) (f). (a), (c), and (e)—PAS; (b), (d), and (f)—ORO: Scale bar: $20 \mu \mathrm{m}$.

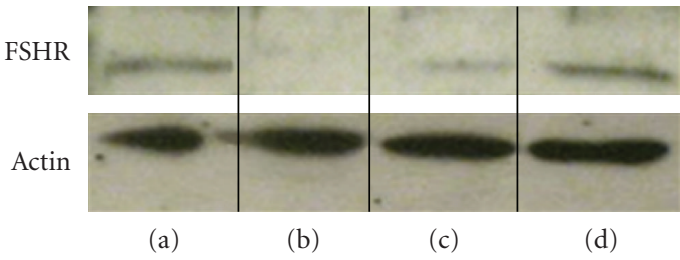

Figure 4: The expression of FSH-R protein in (a) the testis, (b) skeletal muscle of rat, (c) the caput epididymis, and (d) the cauda epididymis. The presence of actin in tested tissues of rat is shown.

of E2 in the media of cells cultured without DHT in supplementation with $0.4 \mathrm{IU} \mathrm{FSH} / \mathrm{mL}$ or $0.8 \mathrm{IU}$ FSH/mL (Figure 5).

After 3 days there were no differences in E2 level in media of epithelial cells of caput epididymis cultured without DHT and supplemented with FSH, while the statistical significant increase in E2 level was noticed in medium of epithelial cells of caput epididymis stimulated with $0.8 \mathrm{IU} / \mathrm{mL} \mathrm{FSH}$, after 5 days of culture. The decrease of estradiol concentration was observed in media of epithelial cells of cauda epididymis cultured without DHT and supplemented with 0.4 IU or $0.8 \mathrm{IU} / \mathrm{mL}$ FSH during 3 or 5 days (Figure 5).

The concentration of E2 in the culture media where the cells of the caput and cauda epididymides were cultured with DHT (+DHT) was compared to the concentration of E2 in the media of cells cultured with DHT in supplementation with $0.4 \mathrm{UI} / \mathrm{mL}$ or $0.8 \mathrm{UI} / \mathrm{mL}$ FSH (Figure 6).

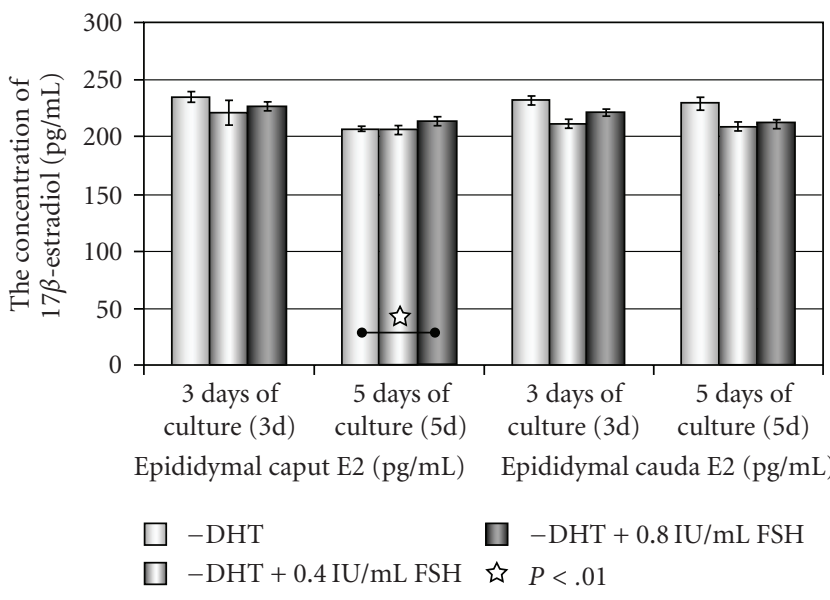

FIGURE 5: The concentration of $17 \beta$-estradiol (E2) in media of epithelial cells of the caput and cauda epididymis cultured without DHT and stimulated with FSH.

The statistical increase of E2 level was observed only in medium of the caput epididymal cells cultured with DHT and $0.4 \mathrm{IU} / \mathrm{mL}$ or $0.8 \mathrm{IU} / \mathrm{mLFSH}$, at the 3 rd day and 5 th day of culture. The concentrations of E2 in media of cauda epididymal epithelial cells cultured with DHT in supplementation with $0.4 \mathrm{IU} / \mathrm{mL}$ or $0.8 \mathrm{IU} / \mathrm{mLFSH}$ on day 3 and 5 were on the similar insignificant level as in media of the cells cultured with DHT only (Figure 6). 


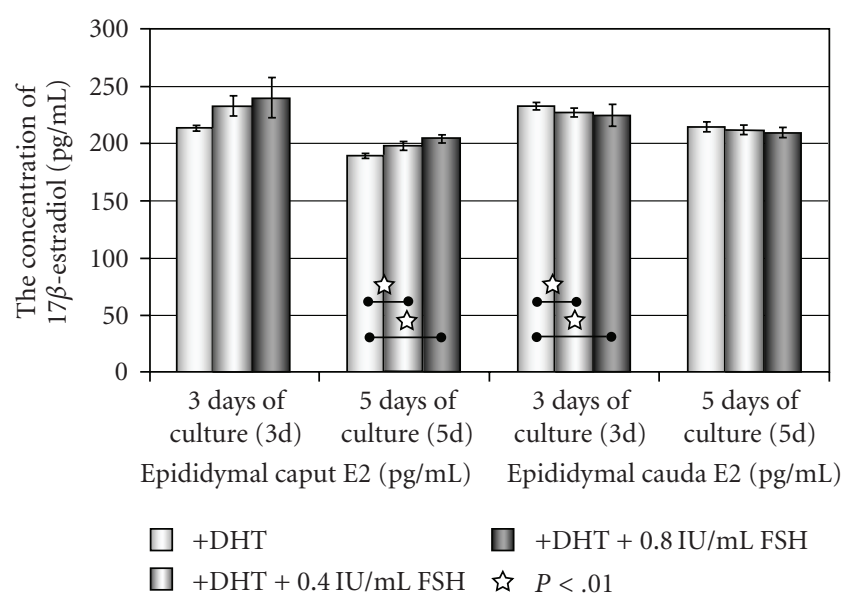

Figure 6: The concentration of $17 \beta$-estradiol (E2) in media of epithelial cells of the caput and cauda epididymis cultured with DHT and stimulated with FSH.

\section{Discussion}

In the male reproductive system, the testis is the source of hormones, testicular proteins, and spermatozoa, while the epididymis is the organ responsible for maturation, storage, and survival of male gametes. The full fertilizing ability of released spermatozoa is dependent on series of morphological, biochemical, and functional changes during the transit through the epididymis, regulated by androgens - testosterone, DHT, and estrogens. Additionally, two pituitary gonadotropins, luteinizing hormone $(\mathrm{LH})$ and follicle-stimulating hormone ( $\mathrm{FSH}$ ), are also involved in the processes. In male LH and its receptors (LHR) are necessary for the synthesis of testosterone in the gonadal interstitial Leydig cells and regulate the morphology epithelial cells of the epididymis and epididymal steroidogenesis. FSH binds to its receptor (FSH-R) in somatic Sertoli cells and stimulates the cells to the production and secretion of numerous proteins into the seminiferous tubular lumen. Dahia and Rao [14] for the first time showed that the FSH receptor is also expressed in epithelial cells of the cauda epididymis of rat and monkey.

Therefore, the goal of the present study was to estimate the influence of FSH on the epididymal epithelial cells morphology and their steroidogenic function in vitro. Firstly, we estimated the expression of FSH-R in the epididymis of men and rats. We observed the FSH-R expression in epithelium of ductuli efferentes and along the human and rat epididymis. The expression of FSH-R protein was shown by us in the caput and cauda epididymis of rat in Western blot analysis with the same antibody. However, the results are not in agreement with studies of the other who presented FSH-R expression only in epithelial cells of the cauda epididymis by more specific RT-PCR, Northern and Western blots methods and immunohistochemistry using FSH-R antibody raised in monkey against three overlapping decapeptides of the ECD region [14]. It is difficult to explain the difference in our experiment. To visualize the FSH-R in epididymis we used rabbit polyclonal anti-FSH-R antibody from Santa Cruz Biotechnology, and the control of specificity reaction was carried out by omitting primary antibody. The immunohistochemistry studies were repeated many times and results were the same and confirmed by Western blot analysis for rat epididymis. The obtained results confirmed the epididymis to be a target organ for FSH; however they needed more detailed studies.

The examinations of FSH receptor knockout mice (FORKO) demonstrate defects in sperm development, leading to the poor quality sperm production [16-18] suggesting that FSH not only participates in spermatogenesis but is also important for normal maturation process of spermatozoa and fertility. However, in the FORKO mice, the changes of the epididymis were also observed. In general morphology, the epididymis of the mice appeared to be normal, but the tubular diameter of cross sections was smaller than in wild type $[16,18,19]$; moreover at 6 months of age the size of epididymal tubules and the highest of epididymal epithelium were significantly reduced in the caput and corpus epididymides $[18,20]$. The reduction of the various morphometric parameters of caput and corpus epididymides was thought to be dependent on the reduction of testosterone in the serum of FORKO mice and abnormal Sertoli cell functions $[18,20]$. For studies on FSH function in male a transgenic rat was established using the construct of porcine $\mathrm{FSH} \beta$ subunit promoter, the $-852 /+10$ bp region, fused to a Herpes simplex virus thymidine kinase (HSVTK) gene [21]. The male transgenic rats were infertile with abnormal spermatogenesis, and the decreased of the testis and epididymis weight was observed. The weights of the prostate and seminal vesicles were unchanged, suggesting the normal level of testosterone in the serum [21]. The recent study of Dahia et al. [22] indicates that deprivation of endogenous follicle stimulating hormone results in the changes in the histology of rat epididymal epithelium.

To estimate the possibility of FSH influence on the epididymal epithelium morphology we used a cell culture model without an interference endogenous testicular and epididymal hormones and factors and a fact that epididymal epithelial cells in vitro resume their secretory function. It was shown that the cells are involved in steroidogenesis and produce and release androgens into the culture medium and convert them into $17 \beta$-estradiol, also under the regulation of hCG [11-13]. The well-documented changes in the morphology of epididymal epithelial cells, cultured without DHT, but in the supplementation with hCG [23] indicate the regulatory influence of pituitary hormone on the epididymis, like in the testicular Leydig cells. The presence of LH receptors in the epididymal epithelial cells in vitro and in vivo was documented in our previous studies [12, 23].

In the present study, the isolated epididymal epithelial cells were cultured in a medium without/with DHT, and additionally supplemented with FSH. The gonadotropin was introduced into the culture medium on day 0 , and the cells were exposed to FSH over the culture time. As it was documented in our earlier studies, the epididymal epithelial cells cultured in the medium with DHT resumed their function. Their cytoplasm was rich in lipid droplets and PASpositive substances, while the cytoplasm of the cells cultured 
without DHT showed decreased amount of these components. The sign of stimulatory effect of FSH, was forming of confluent monolayer and the increase of lipid droplets in the cytoplasm, compared to the cells cultured without DHT. It indicated that FSH can affect the morphology of the epididymal epithelial cells in vitro.

The introduction of FSH into the medium of cultured epididymal epithelial cells changed the level of $17 \beta$ estradiol. The statistically significant increase of E2 level after FSH stimulation was observed in media without DHT and with higher dose of FSH of epithelial cells of caput epididymis at 5th day. The dose-dependent pattern of the increasing of E2 level was detected in media with DHT of epithelial cells of the caput epididymis at 3rd and 5th day of culture. The obtained effects clearly indicated that synthesis of $17 \beta$-estradiol by epithelial cells of the caput epididymis of rat can be stimulated by FSH. However, in media of epithelial cells of the cauda epididymis the level of E2 was insignificantly decreasing. The decreased E2 level during the absence of DHT in culture medium could be connected with the situation that the cells were mobilized more effectively to the production of endogenous androgens to maintain the morphological and functional integrity. The presence of DHT in culture medium and addition of FSH stimulate the cells of the caput epididymis to the aromatization of endogenous androgens into the estrogens. After stimulation with FSH the concentration of E2 increased. It could be connected with the fact that the cytochrome P450 aromatase activity in the caput epididymis is significantly higher than that in corpus and cauda [9]. According to the segment-specific function of the part of reproductive tract, the stimulatory effect of FSH on epithelial cells of the ductuli efferentes and proximal segment of the epididymis is justified. Ductuli efferentes are the major target for estrogen action, where the epithelial cells express estrogen receptors $\alpha$ and $\beta$ with highest concentration of ER $\alpha$ [2427]. The primary function of estrogen acting through ER $\alpha$ is to regulate the morphology and activity of nonciliated cells $[25,28-30]$. Ductuli efferentes are known to reabsorb more than $90 \%$ rete testis fluid and concentrate sperm as well as luminal components before entering the lumen of the epididymis $[24,31]$. The reabsorption of testicular fluid and production of many proteins taking part in the reabsorption process are regulated by estrogens [24, 3236]. The distribution of ERs in duct of epididymis is not uniform and depends on species $[24,26,27,37]$. It can be connected with the fact that the requirement for estrogens in the epididymis is differentiated. While the proximal part, included in maturation spermatozoa process, needs estrogens in higher concentration, in the distal part where the spermatozoa are stored, the concentration is lower. In mice epididymis estrogen sulfotransferase (ETS) was found [38]. The enzyme catalyzes the sulfoconjugation and inactivation of estrogens [39]. Estrogen sulfotransferase was localized in the epithelium of the corpus and cauda epididymis. There was no immunoexpression in the epithelium of the caput epididymis [38]. This segmental specific pattern of ETS expression in epididymis suggests important physiological role in regulation of local estrogen homeostasis [38].

\section{Conclusion}

The identification of FSH receptors in human and rat epididymides supports the results that epididymis is a target not only for LH but additionally for FSH. On the basis of the results we showed for the first time that the morphology of epididymal epithelial cells and epididymal steroidogenesis in vitro can be regulated by FSH.

\section{Acknowledgment}

The authors are grateful to Dr. Malgorzata Milkiewicz for technical assistance with Western Blotting.

\section{References}

[1] D. W. Hamilton and D. W. Fawcett, "In vitro synthesis of cholesterol and testosterone from acetate by rat epididymis and vas deferens," Proceedings of the Society for Experimental Biology and Medicine, vol. 133, no. 2, pp. 693-695, 1970.

[2] A. I. Frankel and K. B. Eik-Nes, "The metabolism of steroids in the rabbit epididymis," Endocrinology, vol. 87, no. 4, pp. 646$652,1970$.

[3] G. L. Kumari, I. S. Allag, R. P. Das, and J. K. Datta, "Regional differences in steroidogenesis and hormone levels in the epididymis and vas deferens of adult rats," International Journal of Andrology, vol. 3, no. 3, pp. 267-281, 1980.

[4] J. Simard, M. H. Melner, N. Breton, et al., "Characterization of macaque 3 beta-hydroxy-5-ene steroid dehydrogenase $/ \Delta^{5}-$ $\Delta^{4}$ isomerase: structural and expression in steroidogenic and peripherial tissue in primate," Molecular and Cellular Endocrinology, vol. 75, no. 2, pp. 101-110, 1991.

[5] M. H. Vazquez, M. A. de Larminat, E. Gurpide, C. Scorticati, and J. A. Blaquier, "Androgen metabolism in the human epididymis. Effect of in vivo estrogen administration," Journal of Steroid Biochemistry, vol. 25, no. 2, pp. 239-244, 1986.

[6] B. Robaire and N. A. Henderson, "Actions of $5 \alpha$-reductase inhibitors on the epididymis," Molecular and Cellular Endocrinology, vol. 250, no. 1-2, pp. 190-195, 2006.

[7] A. Carpino, F. Romeo, and V. Rago, "Aromatase immunolocalization in human ductuli afferentes and proximal ductus epididymis," Journal of Anatomy, vol. 204, no. 3, pp. 217-220, 2004.

[8] A. Hejmej, M. Gorazd, K. Kosiniak-Kamysz, B. Wiszniewska, J. Sadowska, and B. Bilińska, "Expression of aromatase and oestrogen receptors in reproductive tissues of the stallion and a single cryptorchid visualised by means of immunohistochemistry," Domestic Animal Endocrinology, vol. 29, no. 3, pp. 534547, 2005.

[9] A. C. Pereyra-Martinez, C. E. Roselli, H. L. Stadelman, and J. A. Resko, "Cytochrome p450 aromatase in testis and epididymis of male rhesus monkeys," Endocrine, vol. 16, no. 1, pp. 15-19, 2001.

[10] D. Shayu and A. J. Rao, "Expression of functional aromatase in the epididymis: role of androgens and LH in modulation of expression and activity," Molecular and Cellular Endocrinology, vol. 249, no. 1-2, pp. 40-50, 2006.

[11] B. Wiszniewska, "Primary culture of the rat epididymal epithelial cells as a source of oestrogen," Andrologia, vol. 34, no. 3, pp. 180-187, 2002.

[12] M. Świder-Al-Amawi, M. Marchlewicz, A. Kolasa, L. WendaRóżewicka, and B. Wiszniewska, "Rat epididymal epithelial 
cells and $17 \beta$-estradiol synthesis under hCG stimulation in vitro," Folia Histochemica et Cytobiologica, vol. 45, no. 3, pp. 255-263, 2007.

[13] B. Wiszniewska, "Steroidogenic characteristics of in vitro cultured epididymal epithelial cells of the rat," Reproductive Biology, vol. 1, no. 1, pp. 60-66, 2001.

[14] C. L. Dahia and A. J. Rao, "Demonstration of folliclestimulating hormone receptor in cauda epididymis of rat," Biology of Reproduction, vol. 75, no. 1, pp. 98-106, 2006.

[15] J. D. Bancroft and M. Gamble, Theory and Practice of Histological Techniques, Churchill Livingstone, London, UK, 2002.

[16] H. Krishnamurthy, N. Danilovich, C. R. Morales, and M. R. Sairam, "Qualitative and quantitative decline in spermatogenesis of the follicle-stimulating hormone receptor knockout (FORKO) mouse," Biology of Reproduction, vol. 62, no. 5, pp. 1146-1159, 2000.

[17] M. R. Sairam and H. Krishnamurthy, "The role of folliclestimulating hormone in spermatogenesis: lessons from knockout animal models," Archives of Medical Research, vol. 32, no. 6, pp. 601-608, 2001.

[18] A. Grover, C. E. Smith, M. Gregory, D. G. Cyr, M. R. Sairam, and L. Hermo, "Effects of FSH receptor deletion on epididymal tubules and sperm morphology, numbers, and motility," Molecular Reproduction and Development, vol. 72, no. 2, pp. 135-144, 2005.

[19] H. Krishnamurthy, P. S. Babu, C. R. Morales, and M. Ram Sairam, "Delay in sexual maturity of the follicle-stimulating hormone receptor knockout male mouse," Biology of Reproduction, vol. 65, no. 2, pp. 522-531, 2001.

[20] H. Krishnamurthy, R. Kats, N. Danilovich, D. Javeshghani, and M. R. Sairam, "Intercellular communication between Sertoli cells and Leydig cells in the absence of follicle-stimulating hormone-receptor signaling," Biology of Reproduction, vol. 65, no. 4, pp. 1201-1207, 2001.

[21] L.-Y. Cai, T. Kato, K. Ito, et al., "Expression of porcine FSH $\beta$ subunit promoter-driven herpes simplex virus thymidine kinase gene in transgenic rats," Journal of Reproduction and Development, vol. 53, no. 2, pp. 201-209, 2007.

[22] C. L. Dahia, P. Petrusz, S. H. Hall, and A. J. Rao, "Effect of deprivation of endogenous follicle stimulating hormone on rat epididymis: a histological evaluation," Reproductive BioMedicine Online, vol. 17, no. 3, pp. 331-337, 2008.

[23] M. Świder-Al-Amawi, M. Marchlewicz, B. Wiszniewska, and L. Wenda-Różewicka, "Effect of hCG on the morphology of rat epididymal epithelial cells in vitro," Folia Morphologica, vol. 62, no. 4, pp. 489-491, 2003.

[24] R. A. Hess, "Estrogen in the adult male reproductive tract: a review," Reproductive Biology and Endocrinology, vol. 1, article 52, 2003.

[25] C. A. Oliveira, A. B. Victor-Costa, and R. A. Hess, "Cellular and regional distributions of ubiquitin-proteasome and endocytotic pathway components in the epithelium of rat efferent ductules and initial segment of the epididymis," Journal of Andrology, vol. 30, no. 5, pp. 590-601, 2009.

[26] R. Nie, Q. Zhou, E. Jassim, P. T. K. Saunders, and R. A. Hess, "Differential expression of estrogen receptors $\alpha$ and $\beta$ in the reproductive tracts of adult male dogs and cats," Biology of Reproduction, vol. 66, no. 4, pp. 1161-1168, 2002.

[27] Q. Zhou, R. Nie, G. S. Prins, P. T. K. Saunders, B. S. Katzenellenbogen, and R. A. Hess, "Localization of androgen and estrogen receptors in adult male mouse reproductive tract," Journal of Andrology, vol. 23, no. 6, pp. 870-881, 2002.
[28] K.-H. Lee, R. A. Hess, J. M. Bahr, D. B. Lubahn, J. Taylor, and D. Bunick, "Estrogen receptor $\alpha$ has a functional role in the mouse rete testis and efferent ductules," Biology of Reproduction, vol. 63, no. 6, pp. 1873-1880, 2000.

[29] K. Toda, T. Okada, Y. Hayashi, and T. Saibara, "Preserved tissue structure of efferent ductules in aromatase-deficient mice," Journal of Endocrinology, vol. 199, no. 1, pp. 137-146, 2008.

[30] F. Yasuhara, G. R. O. Gomes, E. R. Siu, et al., "Effects of the antiestrogen fulvestrant (ICI 182,780) on gene expression of the rat efferent ductules," Biology of Reproduction, vol. 79, no. 3, pp. 432-441, 2008.

[31] G. A. Cornwall, H. H. von Horsten, D. Swartz, S. Johnson, K. Chau, and S. Whelly, "Extracellular quality control in the epididymis," Asian Journal of Andrology, vol. 9, no. 4, pp. 500507, 2007.

[32] R. A. Hess and K. Carnes, "The role of estrogen in testis and the male reproductive tract: a review and species comparison," Animal Reproduction, vol. 1, no. 1, pp. 5-30, 2004.

[33] C. A. Oliviera, K. Carnes, L. R. Franca, L. Hermo, and R. A. Hess, "Aquaporin-1 and -9 are differentially regulated by oestrogen in the efferent ductule epithelium and initial segment of the epididymis," Biology of the Cell, vol. 97, no. 6, pp. 385-395, 2005.

[34] P. Picciarelli-Lima, A. G. Oliveira, A. M. Reis, et al., "Effects of 3-beta-diol, an androgen metabolite with intrinsic estrogenlike effects, in modulating the aquaporin-9 expression in the rat efferent ductules," Reproductive Biology and Endocrinology, vol. 4, article 51, 2006.

[35] R. Ruz, M. Gregory, C. E. Smith, et al., "Expression of aquaporins in the efferent ductules, sperm counts, and sperm motility in estrogen receptor-alpha deficient mice fed lab chow versus casein," Molecular Reproduction and Development, vol. 73, no. 2, pp. 226-237, 2006.

[36] Q. Zhou, L. Clarke, R. Nie, et al., "Estrogen action and male fertility: roles of the sodium/hydrogen exchanger-3 and fluid reabsorption in reproductive tract function," Proceedings of the National Academy of Sciences of the United States of America, vol. 98, no. 24, pp. 14132-14137, 2001.

[37] A. Kolasa, B. Wiszniewska, M. Marchlewicz, and L. WendaRóżewicka, "Localisation of oestrogen receptors (ER $\alpha$ and $\mathrm{ER} \beta$ ) in the human and rat epididymides," Folia Morphologica, vol. 62, no. 4, pp. 467-469, 2003.

[38] M. H. Tong and W.-C. Song, "Estrogen sulfotransferase: discrete and androgen-dependent expression in the male reproductive tract and demonstration of an in vivo function in the mouse epididymis," Endocrinology, vol. 143, no. 8, pp. 3144-3151, 2002.

[39] W.-C. Song, "Biochemistry and reproductive endocrinology of estrogen sulfotransferase," Annals of the New York Academy of Sciences, vol. 948, pp. 43-50, 2001. 


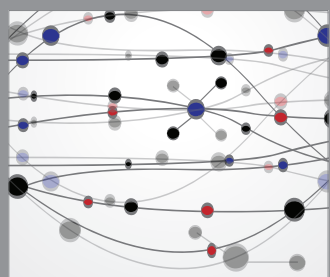

The Scientific World Journal
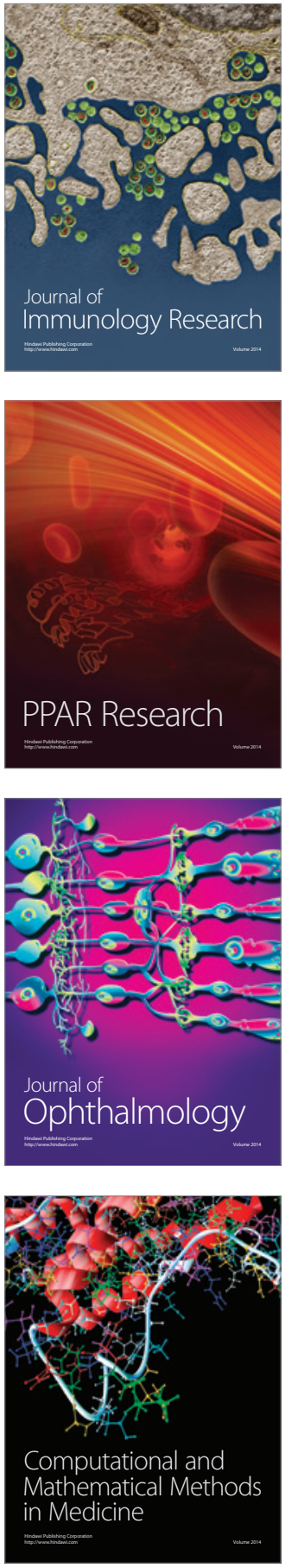

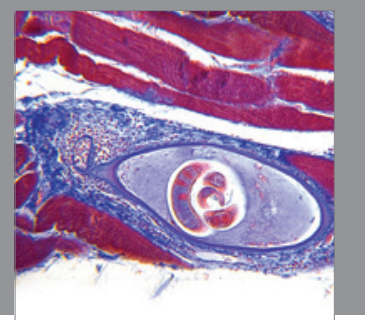

Gastroenterology

Research and Practice
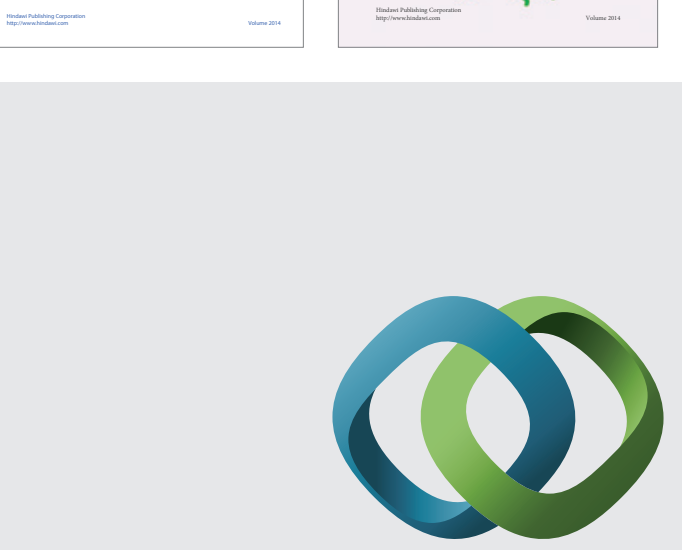

\section{Hindawi}

Submit your manuscripts at

http://www.hindawi.com
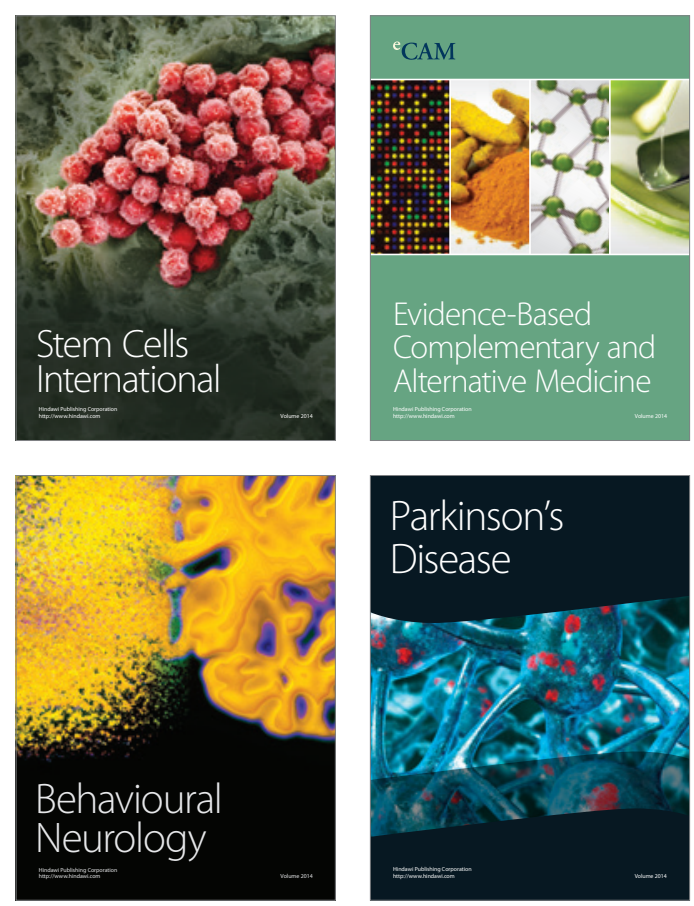

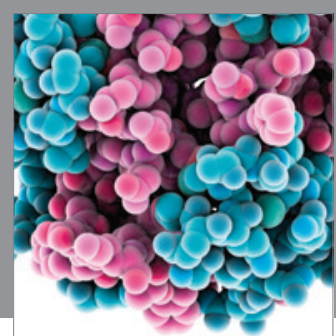

Journal of
Diabetes Research

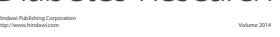

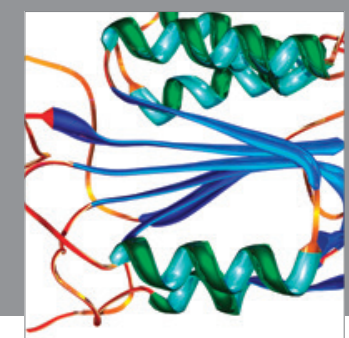

Disease Markers
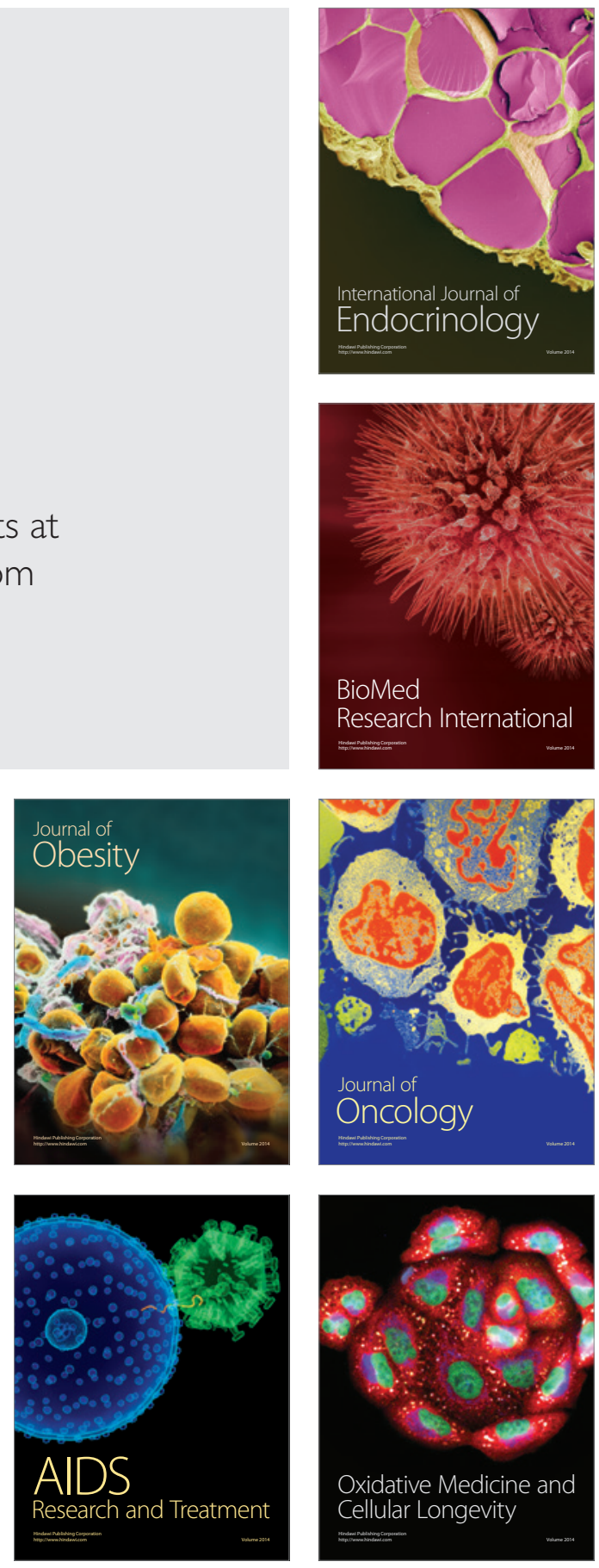